\title{
Relationship between intramammary infection prevalence and somatic cell score in commercial dairy herds
}

\author{
G. E. Shook, ${ }^{* 1}$ R. L. Bamber Kirk, ${ }^{*}$ F. L. Welcome, $\dagger$ Y. H. Schukken, $\ddagger^{2}$ and P. L. Ruegg* \\ *Dairy Science Department, University of Wisconsin, Madison 53706 \\ †Quality Milk Production Services, College of Veterinary Medicine, Cornell University, Ithaca, NY 14850 \\ ‡Department of Population Medicine and Diagnostic Sciences, Cornell University, Ithaca, NY 14853
}

\section{ABSTRACT}

We examined consistency of the relationship between intramammary infection (IMI) and somatic cell score (SCS) across several classes of cow, herd, and sampling time variables. Microbial cultures of composite milk samples were performed by New York Quality Milk Production Services from 1992 to 2004. SCS was from the most recent Dairy Herd Improvement test before IMI sampling. Records were analyzed from 79,308 cows in 1,124 commercial dairy herds representing a broad range of production systems. Three binary dependent variables were presence or absence of contagious IMI, environmental IMI, and all IMI. Independent variables in the initial models were SCS, SCS ${ }^{2}$, lactation number, days in milk, sample day milk yield, use of coliform mastitis vaccine, participant type (required by regulation or voluntary), production system (type of housing, milking system, and herd size), season of sampling, year of sampling, and herd; also the initial models included interactions of SCS and SCS $^{2}$ with other independent variables, except herd and milk yield. Interaction terms characterize differences in the IMI-SCS relationship across classes of the independent variables. Models were derived using the Glimmix macro in SAS (SAS Institute Inc., Cary, NC) with a logistic link function and employing backward elimination. The final model for each dependent variable included all significant independent variables and interactions. Simplified models omitted $\mathrm{SCS}^{2}$ and all interactions with SCS. Interactions of SCS with days in milk, use of coliform mastitis vaccine, participant type, season, and year were not significant in any of the models. Interaction of SCS with production system was significant for the all IMI model, whereas interaction of SCS with lactation number was signifi-

\footnotetext{
Received February 27, 2017.

Accepted August 16, 2017.

${ }^{1}$ Corresponding author: geshook@wisc.edu

${ }^{2}$ Current address: GD Animal Health, 7418 EZ Deventer, the Netherlands, and Department of Animal Sciences, Wageningen University, 6708 PB Wageningen, the Netherlands.
}

cant for the environmental and all IMI models. Each 1-point increase in SCS (or doubling of somatic cell count) was associated with a $2.3,5.5$, and $9.1 \%$ increase in prevalence of contagious, environmental, and all IMI, respectively. Empirical receiver operator characteristic curves and areas under the curve were derived for final and simplified models. The areas under the curve for simplified and final models within each type of IMI differed by 0.009 or less. We concluded that the relationship of IMI with SCS was generally stable over time and consistent across seasons, production systems, and cow factors.

Key words: intramammary infection, somatic cell score, mastitis pathogens, udder health

\section{INTRODUCTION}

Mastitis is generally caused by IMI with pathogenic microorganisms and is recognized based on detection of the inflammatory response to that infection. Milk SCC, lactose percentage, lactate dehydrogenase, and $N$-acetyl- $\beta$-D-glucosaminidase have been evaluated as diagnostic indicators of IMI in dairy cows. Among these, a logarithmic transformation of SCC has been found to provide superior diagnostic performance (Berning and Shook, 1992; Nyman et al., 2014, 2016). Intramammary infections are the principal cause of subclinical and clinical mastitis and the predominant factor associated with variation in SCC (Harmon, 1994; Schepers et al., 1997). Somatic cell count is widely used by dairy producers and veterinarians to identify subclinical mastitis in individual cows (Schukken et al., 2003; Ruegg and Pantoja, 2013).

Many studies have documented effects of cow, herd, and sampling time variables on SCC, IMI, and clinical mastitis (CM). Milk SCC tends to be greatest in the first $10 \mathrm{~d}$ of lactation, drops to a low around the peak of lactation, then slowly increases with DIM (Laevens et al., 1997; Schepers et al., 1997; Reksen et al., 2008; Schukken et al., 2009). Average SCS increases with parity (Laevens et al., 1997; de Haas et al., 2004; Nyman et al., 2014), and this increase is greater for cows with 
CM or IMI (Laevens et al., 1997; Nyman et al., 2014). A decrease in milk yield is typically associated with an increase in SCC (Raubertas and Shook, 1982; Pantoja et al., 2009), or an increase in milk yield is associated with a decrease in SCC (Green et al., 2006).

Studies have reported associations between individual cow SCC and farm management practices (Barkema et al., 1999; Schreiner and Ruegg, 2003; Rowbotham and Ruegg, 2015). Although the very lowest SCC values have been found in small herds (Nightingale et al., 2008), smaller herds typically have higher SCC and average SCC decreases as herd size increases (Norman and Walton, 2014). Incidence rate of CM was greater in tiestall barns than freestall barns (Olde Riekerink et al., 2008). Efficacy of the J5 Escherichia coli vaccine has been demonstrated in commercial herds (González et al., 1989; Hogan et al., 1992; Wilson et al., 2007). Although these herd-level factors have been shown to influence udder health, it has not been demonstrated how they might influence the relationship of IMI with SCS.

The sampling time factors season and year are well known to be associated with differences in udder health (O'Connell et al., 2015). Mastitis and SCC typically peak during seasons with hot and humid weather (Olde Riekerink et al., 2007; Norman and Walton, 2014; Nyman et al., 2014). Species of pathogens isolated from milk samples submitted to a state veterinary diagnostic laboratory differed among seasons, and seasonal differences varied among species (Makovec and Ruegg, 2003). Improvements in udder health management, partly driven by milk quality premium programs, have led to decreases in SCC across years (Nightingale et al., 2008; Norman and Walton, 2014). From 1994 to 2001, reductions of 40 to $60 \%$ in frequency of contagious pathogens were observed in samples submitted to the Wisconsin Veterinary Diagnostic Laboratory (Madison); little or no reduction was observed for environmental pathogens (Makovec and Ruegg, 2003).

Mastitis pathogens are generally classified as contagious or environmental based on the likely source of exposure. Contagious pathogens are generally considered to have longer subclinical states and are often gram-positive, whereas environmental pathogens are considered to be opportunistic pathogens (such as coliforms or environmental Streptococcus spp.) that may trigger a greater inflammatory response that results in obvious clinical signs. A survey in northeast United States spanning 1991 to 1995 found prevalences of contagious and environmental IMI were 26 and $22 \%$, respectively (Wilson et al., 1997). A Wisconsin study spanning 1994 to 2001 found prevalences of contagious and environmental IMI were approximately 17 and $31 \%$, respectively (Makovec and Ruegg, 2003).
Few large-scale studies in commercial dairy herds have determined the effect of these factors on the relationship of SCC with IMI (Steeneveld et al., 2008; Nyman et al., 2016). Nyman et al. (2016) examined performance of SCC as a diagnostic tool for IMI with or without adjustment for breed, parity, milk yield, fat percentage, and milk urea concentration. Steeneveld et al. (2008) examined consistency of the relationship of CM with composite milk SCS across categories of parity, month in lactation, and season. No studies have examined consistency of the IMI-SCS relationship across a range of years, production systems, or herd sizes.

The objective of our study was to characterize the relationship of IMI with SCS in composite milk samples in commercial herds representing the entire spectrum of management levels and production systems over a span of years. Further, we examined the effects on that relationship due to differences in lactation number, stage of lactation, production system, herd size, sampling year, sampling season, and certain herd management practices.

\section{MATERIALS AND METHODS}

\section{Data}

Herd data and milk samples for bacterial culture were collected by New York Quality Milk Production Services (QMPS) field personnel (Schukken et al., 2007) between 1992 and 2004. Data included results of bacterial culture of individual composite milk samples, matching individual cow data retrieved from DHIA records, and herd management information obtained by QMPS questionnaire at the time of sampling. Herds with bulk milk SCC greater than 750,000 cells/mL for 2 of a series of 4 consecutive official samples were required by New York State law to participate in the program; this standard was constant throughout the study period. Participation was voluntary for other herds. Milk sample collection and isolate identification were performed by QMPS laboratory personnel as described previously (Wilson et al., 1997; Schukken et al., 2009).

The IMI culture protocol at QMPS identified 18 microbial species. Pathogens were grouped as either contagious or environmental based on the presumed characteristic of transmission (Table 1). Cows with pathogens in both groups were classified as follows. If the contagious pathogen was not Corynebacterium bovis, the cow was classified as contagious; if $C$. bovis was paired with Staphylococcus spp., gram-positive Bacillus, or Enterobacter spp., the cow was classified as contagious; any other pairing with $C$. bovis was classified as environmental. These pairing decisions were made according to which pathogen had a higher aver- 
Table 1. Numbers of cows and mean and SD for SCS by species and categories of pathogens

\begin{tabular}{lrcc}
\hline Pathogen & Cows & Mean SCS & SD SCS \\
\hline No growth sum or average & 48,500 & 2.59 & 1.68 \\
Contagious pathogen & & & \\
Streptococcus agalactiae & 1,212 & 4.93 & 1.57 \\
Staphylococcus aureus & 4,095 & 4.81 & 1.62 \\
Corynebacterium bovis & 4,991 & 3.50 & 1.61 \\
Mycoplasma spp. & 28 & 3.31 & 1.74 \\
Contagious sum or average & 10,326 & 4.07 & 1.91 \\
Environmental pathogen & & & 1.60 \\
Streptococcus. spp. & 4,611 & 4.38 & 2.06 \\
Staphylococcus spp. & 13,630 & 3.29 & 1.99 \\
Escherichia coli & 452 & 4.05 & 1.92 \\
Klebsiella spp. & 375 & 4.28 & 1.93 \\
Pseudomonas spp. & 154 & 3.30 & 1.75 \\
Pasteurella spp. & 36 & 5.46 & 2.00 \\
Proteus spp. & 112 & 4.03 & 1.88 \\
Serratia spp. & 88 & 4.71 & 1.76 \\
Gram-negative Bacillus & 225 & 3.89 & 1.58 \\
Trueperella pyogenes & 197 & 4.05 & 1.73 \\
Gram-positive Bacillus & 472 & 2.82 & 1.53 \\
Enterobacter spp. & 33 & 4.32 & 1.80 \\
Citrobacter spp. & 23 & 4.36 & \\
Streptococcus Group G & 74 & 5.50 & 3.66 \\
Environmental sum or average & 20,482 & 3.06 & \\
Total & 79,308 & & \\
\hline
\end{tabular}

age SCS in our data. Clinical status of cows at the time of sampling was not known; therefore, the data included clinically and subclinically affected cows as well as unaffected cows. Milk visibly abnormal at the time of DHI sampling was not tested for SCC, as the equipment may clog due to clotting of milk. Hence, nearly all samples were either from cows that were healthy or subclinically affected.

Initially the data contained approximately 2 million cow records (including results of DHIA testing and microbiological analysis of milk samples) and 19,788 herd records. Cow records without DHIA test-day SCC were removed, eliminating more than $50 \%$ of the records. To eliminate time series correlation between records, a herd was allowed to reappear in the data at a minimum of 3-yr intervals. The vast majority of records removed by this edit were herds in violation of the bulk tank SCC standard and were required to test monthly for at least 6 mo or until at least 3 of 4 consecutive tests met the standard. To reduce the potential for introduction of bias caused by selective testing within herds, only herds with $\geq 30$ cows that tested $>60 \%$ of lactating cows were included in the analysis. Cow records with 3 or more cultured pathogens recovered from a single milk sample were defined as contaminated and were discarded, as were records listing the culture result as contaminated. Also, records from cows sampled later than 400 DIM were discarded. Only records from composite milk samples were retained. The test-day SCC used in our study was the most recent value recorded before QMPS sampling. Analysis of SCC was per- formed at the Dairy One Cooperative Inc. laboratory (Ithaca, NY). Somatic cell count was converted to SCS $=\log _{2}(\mathrm{SCC} / 100)+3$, where SCC is cells per microliter (Shook, 1993). The final edit was to discard cows with $\mathrm{SCC} \geq 2,263 \times 10^{3}$ cells $/ \mathrm{mL}$ (SCS $\geq 7.5$ ), as the number of records was limited (approximately $4 \%$ of the edited data set) and including these could have reduced model fit in lower, more common ranges of SCS. After all edits, some herds had fewer than the original minimum of 30 cows. The final data set consisted of 79,308 cow records from 1,124 herds.

\section{Statistical Analysis}

Three binary dependent variables were investigated: presence versus absence of contagious (CONT), environmental (ENV), and all pathogens. The CONT model distinguished between cows with a contagious infection and those without, including both environmental infections and no growth. Likewise, the ENV model distinguished between cows with environmental infections and those without, including contagious infections and no growth. The all-pathogen model distinguished between cows with either type of pathogen and no growth.

Independent variables were considered in 3 groups: cow, herd, and sampling time. The cow variables consisted of DHI test-day SCS, test-day milk yield, lactation number, and DIM. The SCS and milk yield were from the last DHI test day preceding the IMI sample. Categories for lactation number were each of the first 4 
lactations and a fifth category for lactations $\geq 5$. Days in milk was broken into five $60-\mathrm{d}$ periods and a sixth period for 301 to 400 DIM.

Herd-level variables consisted of coliform mastitis vaccine, participant type, and production system. Three categories of coliform mastitis vaccine were used, not used, and unknown or intermittent use. Participant type depended on whether a herd was required by New York State law to be sampled by QMPS, and the 3 categories were required, voluntary, and unknown. Production system was based on housing type, milking system, and herd size gathered from the QMPS survey. The most frequent housing types in the data were freestall and tiestall barns. As parlor milking systems were most often associated with freestall barns and pipeline systems were most often associated with tiestall barns, we used the terms parlor and pipeline to also imply housing type. Herd size categories, large and small, were determined separately for the 2 milkinghousing systems. This division was made to obtain approximately equal numbers of cows in each herd size category. Thus, the production system categories were parlor with $<240$ cows, parlor with $\geq 240$ cows, pipeline with $<78$ cows, and pipeline with $\geq 78$ cows.

The sampling time variables were season and year of IMI sampling. Season categories were January to March, April to June, July to September, and October to December. To attain approximately equal numbers of cows within year groups, 4 year groups were designated: 1992 to 1995, 1996 to 1998, 1999 to 2001, and 2002 to 2004.

The models were fitted using the Glimmix macro in SAS with a logistic link function (SAS, 2002). In a preliminary analysis, SCS was examined with linear, quadratic, and cubic terms. Cubic terms were not significant and were not included in any subsequent models. Categorical independent variables in the initial models were lactation number, DIM, coliform vaccine use, participant type, production system, season of sampling, year of sampling, and herd, which was fitted as a random effect. Continuous independent variables were test day composite SCS, SCS ${ }^{2}$, test-day milk yield, and interactions of SCS and $\mathrm{SCS}^{2}$ with each of the categorical independent variables except herd. Thereby, these models provide separate linear and quadratic regression coefficients for different levels of the significant categorical variables. Due to the large number of independent variables and the several categories of those variables, interactions among categorical variables were not included in any models. Herd was nested within categories of production system, participant type, coliform mastitis vaccine, season, and year. Nesting herds within categories of these factors was necessary because individual herds occurred in only 1 level of each fac- tor. Backward elimination of independent variables was employed to obtain final models that included only significant variables. Multicollinearity among independent variables was not specifically examined separately, however, backward elimination would exclude variables that show high multicollinearity. A $P$-value of 0.0001 was used due to the large number of records and to exclude from the final models small effects that have no practical importance.

A simplified model was computed for each dependent variable to examine the relationship of IMI with SCS; these models included only a linear term for SCS and omitted interactions of SCS with other independent variables. Thus, the simplified models provide a single linear regression coefficient for the IMI-SCS relationship. In addition, these models included herd and only the significant independent variables identified in the final models. Also, the number of categories for each independent variable was reduced in such a way that categories with similar effects were combined, but all categories with significant effects in the final models were retained. Simplified models were not subjected to the backward elimination process. Performance of SCS as a diagnostic for IMI was compared between the final and simplified models as described in the following section; this comparison addresses the question of whether separate regressions of IMI on SCS should be used in different situations or a single regression is adequate in all situations.

Parameter estimates are reported on the scale of logistic transformation of prevalence (PREV); that is, $\ln [\mathrm{PREV} /(1-\mathrm{PREV})]$. Relationships of predicted prevalence of IMI with SCS were plotted for both final and simplified models. Parameter estimates used for calculating predicted prevalences were regression coefficients for SCS, and constants for the following levels of the significant independent variables: second lactation, 121 to 180 DIM, voluntary participation type, milk production of $30 \mathrm{~kg} / \mathrm{d}$, pipeline milking system in herds with $\geq 78$ cows, and sampling in 2002 to 2004. These levels were chosen because they represented the median category in terms of cow numbers, most recent category, or had intermediate IMI prevalence. Vaccine use and season were not significant in any of the models, so they were not involved in these calculations. Parameter estimates were summed over the several independent variables. The total, $\mathrm{T}$, was transformed to predicted prevalence, $\mathrm{P}$, by $\mathrm{P}=\mathrm{e}^{\mathrm{T}} /\left(1+\mathrm{e}^{\mathrm{T}}\right)$, where $\mathrm{e}$ is the base of the natural logarithm.

\section{Receiver Operating Characteristic Curves}

Diagnostic performance of the logistic regression models was evaluated using empirical receiver oper- 
Table 2. Numbers of cows, IMI prevalence, and mean SCS by lactation number and DIM

\begin{tabular}{lrrrrr}
\hline & & \multicolumn{3}{c}{ IMI prevalence (\%) } & \\
\cline { 3 - 4 } Variable & Cows & Contagious & Environmental & \multirow{2}{*}{ All } & \multirow{2}{*}{ Mean SCS } \\
\hline Lactation number & & & & & \\
1 & 28,623 & 8.6 & 26.2 & 34.8 & 2.61 \\
2 & 21,111 & 12.7 & 24.2 & 36.9 & 3.01 \\
3 & 13,777 & 14.7 & 26.4 & 41.1 & 3.34 \\
4 & 8,079 & 17.1 & 27.1 & 44.2 & 3.57 \\
25 & 7,718 & 18.0 & 31.6 & 49.6 & 3.81 \\
DIM & & & & & \\
$1-60$ & 14,965 & 10.2 & 24.3 & 34.5 & 2.90 \\
$61-120$ & 15,660 & 11.5 & 26.3 & 37.8 & 2.73 \\
$121-180$ & 14,457 & 13.2 & 27.4 & 40.6 & 2.94 \\
$181-240$ & 14,112 & 13.1 & 27.0 & 40.1 & 3.11 \\
$241-300$ & 11,508 & 14.4 & 27.0 & 41.5 & 3.37 \\
$301-400$ & 8,606 & 14.9 & 27.4 & 42.3 & 3.62 \\
\hline
\end{tabular}

ating characteristic (ROC) curves and areas under the curve (AUC; Greiner et al., 2000; Gardner and Greiner, 2006; Dohoo et al., 2009). The ROC curves were derived for both final and simplified models for each of the 3 pathogen types. Model parameters were used to calculate the logistic transformation of infection probability for each individual record. This result was transformed to predicted prevalence for each record, as shown in the previous paragraph. Because herd was modeled as a random effect, parameter estimates for herds were not available; therefore, the individual model probabilities represent an average herd given all other effects in the model. Records were ranked by predicted prevalence and thresholds were set at $5 \%$ increments of prevalence; at each threshold, empirical values of sensitivity (percentage of all IMI-positive animals with model probability greater than the threshold) and specificity (percentage of all IMI-negative animals with model probability less than the threshold) were determined. In the ROC curve, sensitivity is plotted against the false positive rate (i.e., 1 - specificity) across the full range of thresholds, $(0,0)$ to $(1,1)$ (Gardner and Greiner, 2006; Dohoo et al., 2009). Empirical AUC values were calculated from ROC plots using the area of a trapezoid between successive thresholds and summing all trapezoid areas under the curve. Standard errors for the AUC were calculated using the equations of Hanley and McNeil (1982).

\section{RESULTS}

\section{Descriptive Statistics}

Descriptive statistics by species and categories of pathogen are in Table 1. Contagious pathogens were cultured in $13.0 \%$ and environmental pathogens were in $25.8 \%$ of samples. Average sample-day milk yield was approximately $30 \mathrm{~kg} / \mathrm{d}$, with a standard deviation of approximately $10 \mathrm{~kg} / \mathrm{d}$. Pearson correlation between IMI and SCS was 0.21 for the CONT model, 0.20 for the ENV model, and 0.32 for the all-pathogen model. Prevalence of IMI and average SCS by lactation number and DIM categories are in Table 2.

Data were characterized by herd factors, as shown in Table 3. The majority of sampling was performed on a voluntary basis both by cow $(64.8 \%)$ and herd (57.6\%) records (Table 3). Little difference was found in average SCS between unknown and voluntary participant types; however, as expected, a substantial difference existed between voluntary and required herds. Average herd sizes were 77 and 339 cows, respectively, in small and large parlor systems and 39 and 100 cows in small and large pipeline systems. Within production system types, larger herds had lower IMI prevalence and lower SCS. Smaller herds with parlors and larger herds with pipeline systems had similar average SCS. The coliform mastitis vaccine was used routinely in $13.2 \%$ of herds and $18.6 \%$ of cows.

\section{Logistic Regression Models}

Overview. Parameter estimates for the final models are in Table 4 for CONT IMI, Table 5 for ENV IMI, and Table 6 for all IMI; estimates for simplified models are in Supplemental Tables S1, S2, and S3 (https://doi .org/10.3168/jds.2017-12810), respectively. Parameter estimates for the simplified and final models were similar for each IMI, and standard errors for the simplified models were smaller in many cases. The SCS, SCS ${ }^{2}$, lactation number, DIM, and production system were significant in final models for all 3 dependent variables. The parameter for $\mathrm{SCS}^{2}$ was negative in final models for all 3 types of IMI. Interactions of SCS with year, DIM, and participation type were not significant in any 
Table 3. Numbers of cows and herds, IMI prevalence, and mean SCS by categories of herd factors

\begin{tabular}{|c|c|c|c|c|c|c|c|}
\hline Herd factors and categories & Cows & Herds & $\begin{array}{l}\text { Cows } \\
\text { per herd }\end{array}$ & \multicolumn{3}{|c|}{ IMI prevalence (\%) } & Mean SCS \\
\hline \multicolumn{8}{|l|}{ Participant type } \\
\hline Required & 10,771 & 223 & 48.3 & 23.2 & 26.9 & 50.1 & 3.73 \\
\hline Voluntary & 51,402 & 647 & 79.4 & 10.7 & 25.6 & 36.3 & 2.90 \\
\hline \multicolumn{8}{|l|}{ Production system } \\
\hline Pipeline $\geq 78$ cows & 25,990 & 260 & 100.0 & 12.8 & 24.1 & 36.9 & 3.05 \\
\hline \multicolumn{8}{|l|}{ Coliform mastitis vaccine } \\
\hline Unknown/intermittent & 27,569 & 403 & 68.4 & 13.4 & 23.6 & 37.0 & 3.20 \\
\hline Yes & 14,740 & 148 & 99.6 & 6.4 & 28.7 & 35.1 & 2.74 \\
\hline No & 36,999 & 573 & 64.6 & 14.3 & 27.4 & 41.7 & 3.08 \\
\hline \multicolumn{8}{|l|}{ Year sampled } \\
\hline
\end{tabular}

models. Regression of IMI on milk yield was significant only for ENV, indicating that prevalence of ENV IMI was greater for cows with higher yield (Table 5). Season of sampling, coliform mastitis vaccine, and their interactions with SCS were not significant in any of the models. Differences in the herd and residual variances between the final and simplified models were small for all 3 pathogen types and further justify acceptance of the simplified models. The ratio of herd variance to residual variance was 2.0 for CONT, 0.4 for ENV, and 0.6 for all.

Contagious IMI. Prevalence of IMI varied among levels of lactation number, DIM, production system, and participant type; interactions of SCS with these variables were not significant. The relationship of predicted prevalence with SCS is plotted in Figure 1 for the final and simplified models. Predicted prevalence increased in a nearly linear relationship with SCS in the final model, although the quadratic term for SCS was significant. Across the range of SCS, each 1-point increase in SCS (or doubling of SCC) was associated with a $2.3 \%$ increase in prevalence of contagious IMI (Figure 1).

Environmental IMI. The interactions of SCS and $\mathrm{SCS}^{2}$ with lactation number were significant, but only the interaction effects for first lactation were different from zero. Although IMI prevalence varied among levels of year, DIM, production system, and type of participation, the interactions of SCS with these variables were not significant. Predicted prevalence of IMI for final and simplified models is plotted by SCS in Figure 2 ; the models diverge in the higher ranges of SCS due to the negative quadratic term for SCS in the final model. Across the range of SCS, each 1-point increase in SCS was associated with an average $5.5 \%$ increase in prevalence of environmental IMI.

All IMI. In the final model, $\mathrm{SCS}^{2}$, although not significant by itself, remained in the model due to its

Table 4. Parameter estimates for final model for contagious IMI

\begin{tabular}{|c|c|c|c|}
\hline Independent variables & Estimate & $\mathrm{SE}$ & $P$-value ${ }^{1}$ \\
\hline Intercept & -3.376 & 0.117 & 0.0001 \\
\hline SCS & 0.600 & 0.028 & 0.0001 \\
\hline $\mathrm{SCS}^{2}$ & -0.042 & 0.003 & 0.0001 \\
\hline \multicolumn{4}{|l|}{ Lactation } \\
\hline 1 & -0.491 & 0.040 & 0.0001 \\
\hline 2 & -0.201 & 0.040 & 0.0001 \\
\hline 3 & -0.049 & 0.042 & 0.235 \\
\hline 4 & 0.037 & 0.045 & 0.409 \\
\hline$\geq 5$ & Base & & \\
\hline \multicolumn{4}{|l|}{$\overline{\mathrm{DIM}}$} \\
\hline $1-60$ & -0.427 & 0.045 & 0.0001 \\
\hline $61-120$ & -0.227 & 0.043 & 0.0001 \\
\hline $121-180$ & -0.162 & 0.043 & 0.0002 \\
\hline $181-240$ & -0.082 & 0.043 & 0.055 \\
\hline $241-300$ & -0.026 & 0.043 & 0.552 \\
\hline $301-400$ & Base & & \\
\hline \multicolumn{4}{|l|}{ Production system } \\
\hline Parlor $<240$ cows & -0.827 & 0.137 & 0.0001 \\
\hline Parlor $\geq 240$ cows & -0.894 & 0.228 & 0.0001 \\
\hline Pipeline $<78$ cows & 0.378 & 0.103 & 0.0003 \\
\hline Pipeline $\geq 78$ cows & Base & & \\
\hline \multicolumn{4}{|l|}{ Participant type } \\
\hline Unknown & -0.063 & 0.105 & 0.553 \\
\hline Required & 0.558 & 0.109 & 0.0001 \\
\hline Voluntary & Base & & \\
\hline Herd variance & 1.711 & & \\
\hline Residual variance & 0.839 & & \\
\hline
\end{tabular}

${ }^{1} P$-values test the null hypothesis that the parameter estimate $=0$. 
Table 5. Parameter estimates for final model of environmental IMI

\begin{tabular}{|c|c|c|c|}
\hline Independent variable & Estimate & $\mathrm{SE}$ & $P$-value ${ }^{1}$ \\
\hline Intercept & -2.486 & 0.130 & 0.0001 \\
\hline SCS & 0.489 & 0.058 & 0.0001 \\
\hline $\mathrm{SCS}^{2}$ & -0.026 & 0.007 & 0.0003 \\
\hline Milk & 0.003 & 0.001 & 0.0001 \\
\hline \multicolumn{4}{|l|}{ Year } \\
\hline 1992-1995 & -0.439 & 0.060 & 0.0001 \\
\hline 1996-1998 & -0.494 & 0.063 & 0.0001 \\
\hline 1999-2001 & -0.334 & 0.059 & 0.0001 \\
\hline $2002-2004$ & Base & & \\
\hline \multicolumn{4}{|l|}{ Lactation } \\
\hline 1 & -0.365 & 0.119 & 0.002 \\
\hline 2 & -0.117 & 0.123 & 0.339 \\
\hline 3 & -0.143 & 0.133 & 0.281 \\
\hline 4 & -0.221 & 0.151 & 0.145 \\
\hline$\geq 5$ & Base & & \\
\hline \multicolumn{4}{|l|}{$\mathrm{DIM}$} \\
\hline $1-60$ & -0.089 & 0.035 & 0.010 \\
\hline $61-120$ & 0.049 & 0.035 & 0.157 \\
\hline $121-180$ & 0.045 & 0.034 & 0.180 \\
\hline $181-240$ & 0.063 & 0.033 & 0.057 \\
\hline $241-300$ & 0.035 & 0.034 & 0.296 \\
\hline $301-400$ & Base & & \\
\hline \multicolumn{4}{|l|}{ Production system } \\
\hline Parlor $<240$ cows & 0.089 & 0.068 & 0.188 \\
\hline Parlor $\geq 240$ cows & -0.124 & 0.110 & 0.263 \\
\hline Pipeline $<78$ cows & 0.218 & 0.052 & 0.0001 \\
\hline Pipeline $\geq 78$ cows & Base & & \\
\hline \multicolumn{4}{|l|}{ Participant type } \\
\hline Unknown & 0.058 & 0.055 & 0.293 \\
\hline Required & -0.302 & 0.058 & 0.0001 \\
\hline Voluntary & Base & & \\
\hline \multicolumn{4}{|c|}{ Interaction SCS $\times$ lactation } \\
\hline $\mathrm{SCS} \times \mathrm{LAC} 1$ & 0.343 & 0.066 & 0.0001 \\
\hline $\mathrm{SCS} \times \mathrm{LAC} 2$ & -0.006 & 0.068 & 0.930 \\
\hline $\mathrm{SCS} \times \mathrm{LAC} 3$ & -0.027 & 0.073 & 0.714 \\
\hline $\mathrm{SCS} \times \mathrm{LAC} 4$ & 0.051 & 0.082 & 0.536 \\
\hline \multirow{2}{*}{\multicolumn{4}{|c|}{ Interaction $\mathrm{SCS}^{2} \times$ lactation }} \\
\hline & & & \\
\hline $\mathrm{SCS}^{2} \times \mathrm{LAC} 1$ & -0.044 & 0.008 & 0.0001 \\
\hline $\mathrm{SCS}^{2} \times \mathrm{LAC} 2$ & -0.001 & 0.009 & 0.941 \\
\hline $\mathrm{SCS}^{2} \times \mathrm{LAC} 3$ & 0.001 & 0.009 & 0.545 \\
\hline $\mathrm{SCS}^{2} \times \mathrm{LAC} 4$ & -0.007 & 0.010 & 0.463 \\
\hline $\mathrm{SCS}^{2} \times \mathrm{LAC} 5$ & Base & & \\
\hline Herd variance & 0.403 & & \\
\hline Residual variance & 0.966 & & \\
\hline
\end{tabular}

${ }^{1} P$-values test the null hypothesis that the parameter estimate $=0$.

interaction with lactation number. The interaction coefficients of SCS and $\mathrm{SCS}^{2}$ with lactation number were significant only for the first lactation. The interaction of SCS with production system was significant, but this interaction with $\mathrm{SCS}^{2}$ was not. The interactions of SCS with year and DIM were not significant, although IMI prevalence did vary among levels of year and DIM. Predicted prevalence of IMI by SCS is plotted in Figure 3. Predicted prevalence for the final model is below the simplified model at the highest ranges of SCS. Across the range of SCS, each 1-point increase in SCS was associated with an average $9.1 \%$ increase in prevalence of all IMI (Figure 3).

\section{ROC Curves}

The ROC curves for simplified models are in Figure 4; curves for the final models are not shown, as they largely overlap their simplified counterparts. The AUC with standard errors are in Table 7 . The AUC for the simplified models were $<0.01$, below those for the corresponding final models. Among the infection types, AUC was highest for CONT IMI and lowest for ENV IMI. Overall, model fit was modest, with AUC ranging from 0.65 to 0.72 . This is significantly better than the uninformative value of 0.5 , but also indicated that SCS alone is an imperfect predictor of IMI status. Our

Table 6. Parameter estimates for final model of all IMI

\begin{tabular}{|c|c|c|c|}
\hline Independent variable & Estimate & $\mathrm{SE}$ & $P$-value ${ }^{1}$ \\
\hline Intercept & -1.255 & 0.125 & 0.0001 \\
\hline SCS & 0.416 & 0.056 & 0.0001 \\
\hline $\mathrm{SCS}^{2}$ & -0.009 & 0.007 & 0.2140 \\
\hline \multicolumn{4}{|l|}{ Year } \\
\hline 1992-1995 & -0.412 & 0.069 & 0.0001 \\
\hline 1996-1998 & -0.285 & 0.074 & 0.0001 \\
\hline 1999-2001 & -0.228 & 0.068 & 0.0008 \\
\hline 2002-2004 & Base & & \\
\hline \multicolumn{4}{|l|}{ Lactation } \\
\hline 1 & -0.893 & 0.111 & 0.0001 \\
\hline 2 & -0.469 & 0.114 & 0.0001 \\
\hline 3 & -0.399 & 0.123 & 0.001 \\
\hline 4 & -0.339 & 0.139 & 0.015 \\
\hline$\geq 5$ & Base & & \\
\hline \multicolumn{4}{|l|}{$\overline{\mathrm{DIM}}$} \\
\hline $1-60$ & -0.116 & 0.032 & 0.0002 \\
\hline $61-120$ & 0.101 & 0.031 & 0.001 \\
\hline $121-180$ & 0.084 & 0.031 & 0.007 \\
\hline $181-240$ & 0.096 & 0.031 & 0.002 \\
\hline $241-300$ & 0.054 & 0.032 & 0.094 \\
\hline $301-400$ & Base & & \\
\hline \multicolumn{4}{|l|}{ Production system } \\
\hline Parlor $<240$ cows & -0.312 & 0.093 & 0.0008 \\
\hline Parlor $\geq 240$ cows & -0.209 & 0.140 & 0.135 \\
\hline Pipeline $<78$ cows & 0.219 & 0.074 & 0.003 \\
\hline Pipeline $\geq 78$ cows & Base & & \\
\hline \multicolumn{4}{|l|}{ Interaction SCS $\times$ lactation } \\
\hline $\mathrm{SCS} \times \mathrm{LAC} 1$ & 0.464 & 0.064 & 0.0001 \\
\hline $\mathrm{SCS} \times \mathrm{LAC} 2$ & 0.134 & 0.065 & 0.040 \\
\hline $\mathrm{SCS} \times \mathrm{LAC} 3$ & 0.111 & 0.070 & 0.113 \\
\hline $\mathrm{SCS} \times \mathrm{LAC} 4$ & 0.112 & 0.078 & 0.152 \\
\hline SCS $\times$ LAC5 & Base & & \\
\hline \multicolumn{4}{|l|}{ Interaction $\mathrm{SCS}^{2} \times$ lactation } \\
\hline $\mathrm{SCS}^{2} \times \mathrm{LAC} 1$ & -0.056 & 0.008 & 0.0001 \\
\hline $\mathrm{SCS}^{2} \times \mathrm{LAC} 2$ & -0.016 & 0.008 & 0.052 \\
\hline $\mathrm{SCS}^{2} \times \mathrm{LAC} 3$ & -0.010 & 0.009 & 0.253 \\
\hline $\mathrm{SCS}^{2} \times \mathrm{LAC} 4$ & -0.012 & 0.010 & 0.239 \\
\hline $\mathrm{SCS}^{2} \times \mathrm{LAC} 5$ & Base & & \\
\hline \multicolumn{4}{|c|}{ Interaction SCS $\times$ production system } \\
\hline SCS $\times$ Parlor $<240$ cows & 0.011 & 0.014 & 0.447 \\
\hline SCS $\times$ Parlor $\geq 240$ cows & -0.060 & 0.015 & 0.0001 \\
\hline SCS $\times$ Pipeline $<78$ cows & 0.045 & 0.012 & 0.0003 \\
\hline SCS $\times$ Pipeline $\geq 78$ cows & Base & & \\
\hline Herd variance & 0.601 & & \\
\hline Residual variance & 0.972 & & \\
\hline
\end{tabular}

${ }^{1} P$-values test the null hypothesis that the parameter estimate $=0$. 


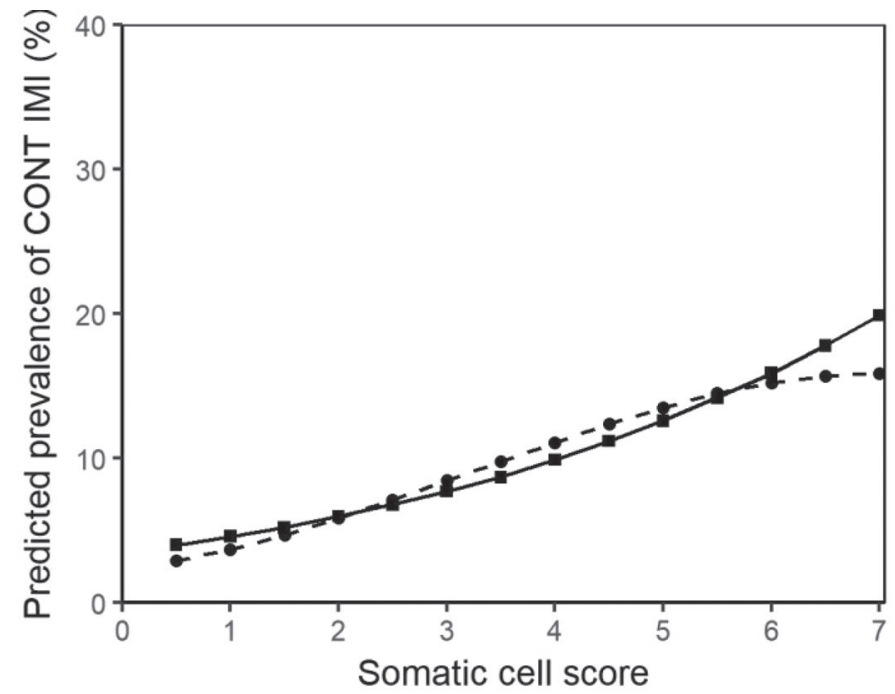

Figure 1. Predicted prevalence for contagious (CONT) IMI by SCS for final $(\bullet)$ and simplified (ם) models.

analysis did not show the presence of single influential values; the large data set showed stable results and results were not affected by single observations.

\section{DISCUSSION}

The final models include significant linear and quadratic terms for SCS and interactions of SCS with cow, herd, and sampling time variables. These interactions allow the relationship between IMI and SCS to vary among levels of other independent variables. In contrast, each corresponding simplified model provides a single linear logistic regression of IMI on SCS. The logistic re-

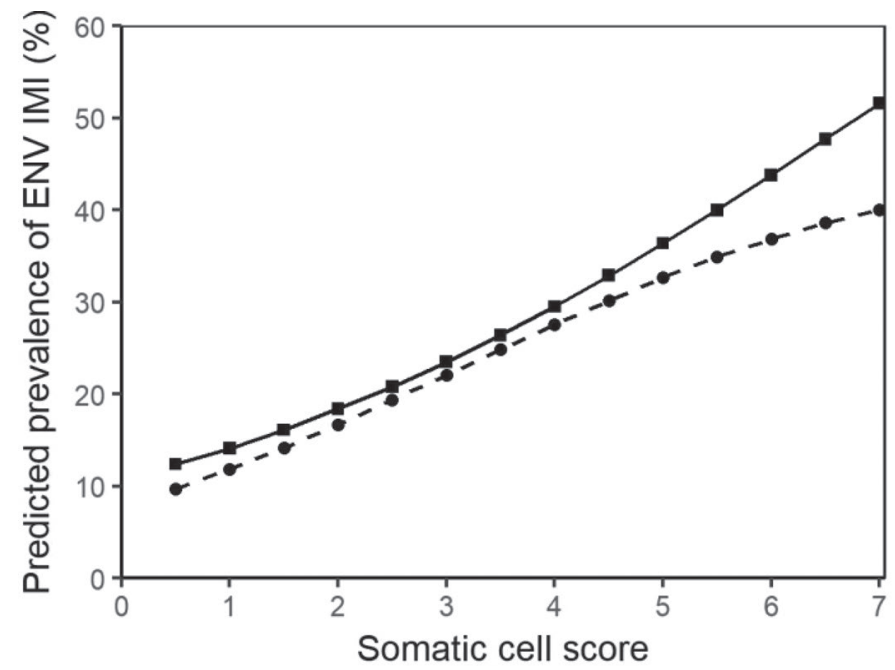

Figure 2. Predicted prevalence for environmental (ENV) IMI by SCS for final (ט) and simplified (ם) models.

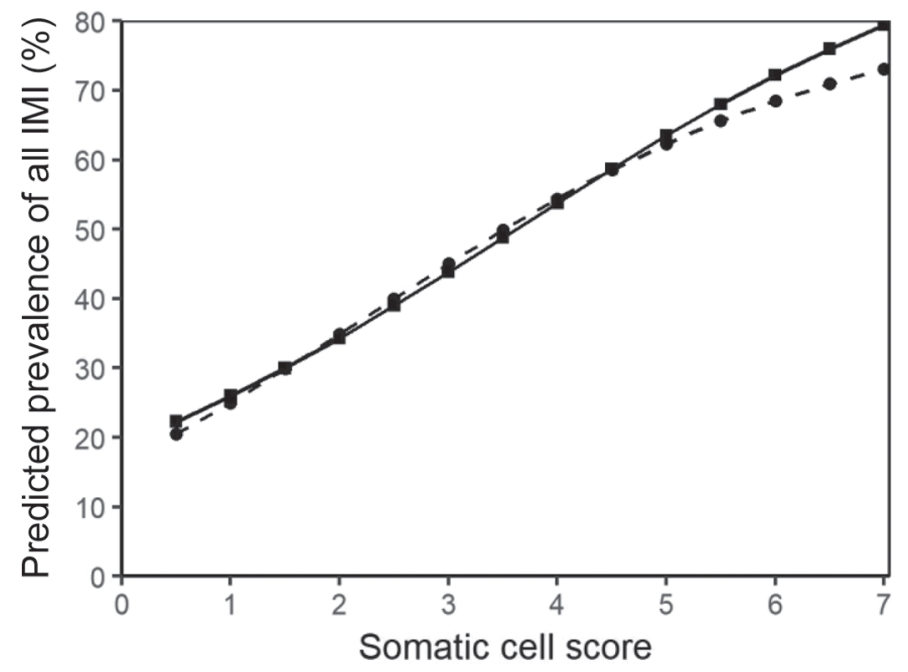

Figure 3. Predicted prevalence for all IMI by SCS for final $(\bullet)$ and simplified (ם) models.

gression analyses demonstrated that the relationship of IMI with SCS varied little between production systems, required versus voluntary testing, years, and other factors indicating that the physiological relationship between IMI and SCS remains fairly constant. Final models for environmental and all IMI indicated that the relationship between SCS and IMI was somewhat dependent on lactation number. Parameter estimates for interaction of SCS with lactation number were significant only for lactation 1 , indicating a greater rate of increase of IMI with SCS in lactation 1 than later lactations (Tables 5 and 6 ).

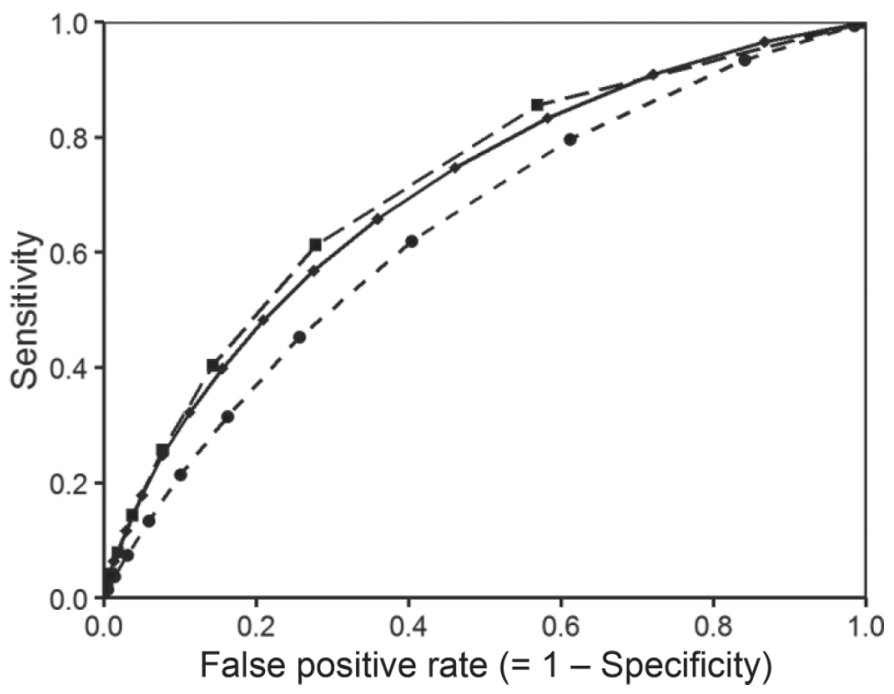

Figure 4. Receiver operating characteristic curves for simplified logistic regression models for contagious $(\mathbf{\square})$, environmental $(\bullet)$, and all $(\bullet)$ IMI. 
For diagnostic tests measured on a continuous scale (e.g., SCS), the ROC curve and AUC provide a comprehensive measure of test performance across the full range of diagnostic test values. One interpretation of AUC is average sensitivity over the entire range of false positive rate. Also, AUC can be interpreted as the probability that a randomly selected diseased cow has a greater test value than a randomly selected healthy cow (Detilleux et al., 1999; Gardner and Greiner, 2006; Dohoo et al., 2009). Differences in AUC between corresponding final and simplified models were small (Table 7), indicating similar diagnostic performance of the models and implying negligible loss of information in the simplified models.

Herd variance was greatest for the CONT model and least for the ENV model, both in actual value and in proportion to residual variance. Since the introduction of modern mastitis control programs (Dodd et al., 1969), effective control of contagious mastitis pathogens and reduced bulk tank SCC have occurred in most developed dairy regions (Makovec and Ruegg, 2003). In contrast, as farm size has increased and farm management has intensified, the occurrence of IMI caused by opportunistic pathogens that originate from the environment has increased (Ruegg, 2017). Control strategies for these environmental pathogens have been less effective and likely contributed to the contrasting herd variances observed in our models.

This is the largest study of its kind, having both SCS and microbial culture data from composite samples in a large number of commercial herds across a broad spectrum of herd management over a span of $13 \mathrm{yr}$. All herds in our study participated in a DHI program that included somatic cell testing of all cows. The data were edited in an attempt to include only herds in which all or nearly all cows were sampled and exclude herds that were sampled selectively; this protected against and substantially reduced the possibility of biases. Also, records with SCS above 7.5 were excluded from these analyses. Our results are thereby representative of cows with SCS below 7.5 in herds that participate in SCC testing through DHI.

Three previous studies have examined performance of SCS for diagnosis of IMI or CM. The earliest of these (Detilleux et al., 1999) sampled only nonclinical cows; likewise, their study was based on quarter samples for SCC and IMI culture for 3 specific pathogens. The AUC were 0.76 for Streptococcus agalactiae, 0.69 for coagulase-positive Staphylococcus spp., and 0.59 for coagulase-negative Staphylococcus spp.

A second study conducted logistic regression of $\mathrm{CM}$ on parity, month in lactation, season, SCS from 2 previous monthly samples, and previous CM incidents (Steeneveld et al., 2008); that study also modeled the
Table 7. Empirical areas under the curve (AUC) for diagnosis of IMI based on SCS for final and simplified logistic regression models

\begin{tabular}{llcc}
\hline IMI & Model & AUC & SE \\
\hline Contagious & Final & 0.722 & 0.003 \\
Contagious & Simplified & 0.719 & 0.003 \\
Environmental & Final & 0.654 & 0.002 \\
Environmental & Simplified & 0.645 & 0.002 \\
All & Final & 0.708 & 0.002 \\
All & Simplified & 0.704 & 0.002 \\
\hline
\end{tabular}

interactions of SCS with parity, season, and month in lactation. Similar to our study, the SCS measures were from monthly composite milk samples collected through the milk recording program. Interactions of SCS with parity and season were marginally significant. An AUC analysis was not performed.

A recent study performed logistic regression of IMI on SCS (Nyman et al., 2016). Intramammary infections were determined from quarter samples and SCS was based on composite milk samples collected at the same time from cows without CM. The AUC analysis was conducted for models that did or did not adjust SCS for parity, breed, milk yield, milk fat percentage, and milk urea concentration. The adjusted and unadjusted AUC values were 0.84 and 0.83 , respectively; diagnostic performance of SCS was improved only slightly by adjusting for these cow factors. The higher AUC in Nyman et al. (2016) can be attributed to their definition of IMI, which was based on quarter samples on 3 consecutive days and strict criteria for determining IMI-positive and -negative outcomes; $20 \%$ of cows were regarded as having inconclusive IMI status and were not included in the data analysis. All 3 of these previous studies collected data for a comparatively short time span, and none examined differences in herd size or production systems

Microbiological examination of both quarter and composite milk samples have been used to define IMI. Quarter samples are a more sensitive indicator of udder health (Schukken et al., 2003; Reyher and Dohoo, 2011), but are more costly than composite samples. A composite milk sample may be culture-negative even if an individual quarter has an IMI due to dilution of the number of colonies shed; hence, sensitivity of IMI diagnosis is lower for composite than quarter samples. Composite samples are widely used to measure SCC in production recording services offered by DHIA. The SCC of composite samples was shown to be related to the number of quarters infected and species of IMI pathogen (Harmon, 1994; Reyher and Dohoo, 2011). The use of composite samples for IMI and SCC in our study resulted in a somewhat lower AUC in comparison to studies that used quarter samples for either IMI or 
SCS. However, udder health management on commercial dairies is often based on composite sampling as the first step in a multistage decision process (Schukken et al., 2003; Ruegg and Pantoja, 2013); therefore, our findings are relevant to herds in which udder health management begins with composite sampling for both IMI and SCS.

As expected, the AUC for CONT IMI was higher than that for ENV IMI in our data. Streptococcus agalactiae, Streptococcus spp., and Staphylococcus aureus typically elicit a substantially greater SCC response than C. bovis and CNS (Harmon, 1994; Schukken et al., 2009). Accordingly, sensitivity of composite IMI samples to detect IMI in quarter samples was greatest for Staph. aureus and Streptococcus dysgalactiae, intermediate for Streptococcus uberis and E. coli, and low for Corynebacterium spp. and Enterococcus spp. (Detilleux et al., 1999; Reyher and Dohoo, 2011); specificity was $>95 \%$ for all of these species. The higher SCS and greater sensitivity for identification of CONT pathogens contributed to the greater AUC for our CONT and all-pathogen models.

Two aspects of the data and analysis may have contributed to somewhat reduced AUC values in this study. The first is modeling DIM in 60-d periods. Somatic cell count and IMI risk typically go through considerable change, especially in both early and late lactation; this dynamic is not fully accounted for in our models, and use of a smaller time interval in the early postpartum period would likely lead to increased prevalence. The second aspect is length and variability of the interval between SCC sampling and IMI sampling. Somatic cell count data were obtained from the most recent DHI test previous to IMI sampling. Whereas the date of IMI sampling was recorded, the date of SCC sampling was not, so the interval from SCC sampling to IMI sampling could not be determined. It is expected from monthly DHI sampling that the interval was approximately uniformly distributed over the range from a few days to perhaps $5 \mathrm{wk}$; an average of 2 to $3 \mathrm{wk}$ is expected. This mimics a system in which bacterial culture tests are performed subsequent to SCC tests. Consequently, an IMI could either begin or fully clear up during this interval, resulting in occurrence of an observed IMI with a low SCC or a negative IMI culture with a high SCC. This contributes to possible bias and loss in precision (sensitivity and specificity) of using SCS as an indicator of IMI in these data. Accordingly, our AUC results may be regarded as conservative, likely understating AUC values based on same-day IMI and SCS sampling. Such bias would be greater for shorter duration environmental pathogens than for longer duration contagious pathogens (Harmon, 1994; de Haas et al., 2004; Ruegg and Pantoja, 2013), thus contributing to a lower AUC for the ENV than the CONT model. Intervals between SCC and IMI sampling, such as occurred in these data, are not uncommon in udder health management.

Due to the nature of the service provided by the New York QMPS, the data included a higher than normal percentage of herds near or above SCC regulation limits. The lack of a statistically significant interaction between participation type and SCS indicates that the relationship of IMI with SCS was similar between required and voluntary herds. The results appear not to be influenced by the over-representation of required herds, and thus relationships are applicable to DHI herds regardless of herd-average SCS.

\section{CONCLUSIONS}

Our primary objective was to examine consistency of the relationship between IMI and SCS across several cow, herd, and sampling time variables for 3 broad categories of pathogens. Interactions of SCS with year of sampling, season of sampling, DIM, milk yield, and participation type were not significant in any models. We concluded that the relationship of IMI with SCS was stable over time and consistent across seasons, production systems, and cow factors. This further suggests that decision thresholds for SCC, such as those used to distinguish subclinical from clinical mastitis, should remain reasonably stable over time and across cow and herd factors.

\section{ACKNOWLEDGMENTS}

Funding for this research was provided by the USDA Cooperative State Research, Education and Extension Service (CSREES; Washington, DC) project WIS04718 and Multi-State project S1008. We acknowledge and appreciate the work of N. Keuler (University of Wisconsin-Madison) for statistical advice, G. Chan (Ellicott City, MD) for editorial review, and T. Passafaro (University of Wisconsin-Madison) for preparing the figures.

\section{REFERENCES}

Barkema, H. W., J. D. van der Ploeg, Y. H. Schukken, T. J. G. M. Lam, G. Benedictus, and A. Brand. 1999. Management style and its association with bulk milk somatic cell count and incidence rate of clinical mastitis. J. Dairy Sci. 82:1655-1663.

Berning, L. M., and G. E. Shook. 1992. Prediction of mastitis using milk somatic cell count, N-acetyl- $\beta$-D-glucosaminidase, and lactose. J. Dairy Sci. 75:1840-1848.

de Haas, Y., R. F. Veerkamp, H. W. Barkema, Y. T. Gröhn, and Y. H. Schukken. 2004. Associations between pathogen-specific cases of clinical mastitis and somatic cell count patterns. J. Dairy Sci. 87:95-105.

Detilleux, J., J. Arendt, F. Lomba, and P. Leroy. 1999. Methods for estimating areas under receiver-operating characteristic curves: Il- 
lustration with somatic cell scores in subclinical intramammary infections. Prev. Vet. Med. 41:75-88.

Dodd, F. H., D. R. Westgarth, F. K. Neave, and R. G. Kingwill. 1969. Mastitis - The strategy of control. J. Dairy Sci. 52:689-695.

Dohoo, I., W. Martin, and H. Stryhn. 2009. Veterinary Epidemiologic Research. 2nd ed. VER Inc., Charlottetown, Prince Edward Island, Canada.

Gardner, I. A., and M. Greiner. 2006. Receiver-operating characteristic curves and likelihood ratios: Improvements over traditional methods for the evaluation and application of veterinary clinical pathology tests. Vet. Clin. Pathol. 35:8-17.

González, R. N., J. S. Cullor, D. E. Jasper, T. B. Farver, R. B. Bushnell, and M. N. Oliver. 1989. Prevention of clinical coliform mastitis in dairy cows by a mutant Escherichia coli vaccine. Can. J. Vet. Res. 53:301-305.

Green, L. E., Y. H. Schukken, and M. J. Green. 2006. On distinguishing cause and consequence: Do high somatic cell counts lead to lower milk yield or does high milk yield lead to lower somatic cell count? Prev. Vet. Med. 76:74-89.

Greiner, M., D. Pfeiffer, and R. D. Smith. 2000. Principles and practical application of the receiver operating characteristic analysis for diagnostic tests. Prev. Vet. Med. 45:23-41.

Hanley, J. A., and B. J. McNeil. 1982. The meaning and use of the area under a receiver operating characteristic (ROC) curve. Radiology 143:29-36.

Harmon, R. J. 1994. Physiology of mastitis and factors affecting somatic cell counts. J. Dairy Sci. 77:2103-2112.

Hogan, J. S., K. L. Smith, D. A. Todhunter, and P. S. Schoenberger. 1992. Field trial to determine efficacy of an Escherichia coli J5 mastitis vaccine. J. Dairy Sci. 75:78-84.

Laevens, H., H. Deluyker, Y. H. Schukken, L. de Muelemeester, R. Vandermeersch, E. de Muelenaere, and A. de Kruif. 1997. Influence of parity and stage of lactation on the somatic cell count in bacteriologically negative dairy cows. J. Dairy Sci. 80:3219-3226.

Makovec, J. A., and P. L. Ruegg. 2003. Results of milk samples submitted for microbiological examination in Wisconsin from 1994 to 2001. J. Dairy Sci. 86:3466-3472.

Nightingale, C., K. Dhuyvetter, R. Mitchell, and Y. H. Schukken 2008. Influence of variable milk quality premiums on observed milk quality. J. Dairy Sci. 91:1236-1244. https://doi.org/10.3168/ jds.2007-0609.

Norman, H. D., and L. M. Walton. 2014. Somatic cell counts of milk from Dairy Herd Improvement herds during 2013. Counc. Dairy Cattle Breeding Res. Rpt. Accessed Jan. 5, 2016. https://www uscdcb.com/publish/dhi/dhil4/sccrpt.htm.

Nyman, A.-K., U. Emanuelson, and K. Persson Waller. 2016. Diagnostic test performance of somatic cell count, lactate dehydrogenase, and N-acetyl- $\beta$-D glucosaminidase for detecting dairy cows with intramammary infection. J. Dairy Sci. 99:1440-1448. https://doi org/10.3168/jds.2015-9808.

Nyman, A.-K., K. Persson Waller, T. W. Bennedsgaard, T. Larsen, and U. Emanuelson. 2014. Associations of udder health indicators with cow factors and with intramammary infection in dairy cows. J. Dairy Sci. 97:5459-5473. https://doi.org/10.3168/jds.2013 $-7885$

O'Connell, A., S. McParland, P. L. Ruegg, B. O'Brien, and D. Gleeson. 2015. Seasonal trends in milk quality in Ireland between 2007 and 2011. J. Dairy Sci. 98:3778-3790. https://doi.org/10.3168/jds .2014-9001.

Olde Riekerink, R. G. M., H. W. Barkema, D. F. Kelton, and D. T. Scholl. 2008. Incidence rate of clinical mastitis on Canadian dairy farms. J. Dairy Sci. 91:1366-1377. https://doi.org/10.3168/ jds.2007-0757.

Olde Riekerink, R. G. M., H. W. Barkema, and H. Stryhn. 2007. The effect of season on somatic cell count and the incidence of clinical mastitis. J. Dairy Sci. 90:1704-1715. https://doi.org/10.3168/jds .2006-567.

Pantoja, J. C. F., C. Hulland, and P. L. Ruegg. 2009. Dynamics of somatic cell counts and intramammary infections across the dry period. Prev. Vet. Med. 90:43-54.

Raubertas, R. F., and G. E. Shook. 1982. Relationship between lactation measures of somatic cell concentration and milk yield. J. Dairy Sci. 65:419-425.

Reksen, O., L. Sølverød, and O. Østerås. 2008. Relationships between milk culture results and composite milk somatic cell counts in Norwegian dairy cattle. J. Dairy Sci. 91:3102-3113. https://doi.org/ 10.3168/jds.2008-1006

Reyher, K. K., and I. R. Dohoo. 2011. Diagnosing intramammary infections: Evaluation of composite milk samples to detect intramammary infections. J. Dairy Sci. 94:3387-3396. https://doi.org/10 .3168/jds.2010-3907.

Rowbotham, R. F., and P. L. Ruegg. 2015. Association of bedding types with management practices and indicators of milk quality on larger Wisconsin dairy farms. J. Dairy Sci. 98:7865-7885. https:// doi.org/10.3168/jds.2015-9866.

Ruegg, P. L. 2017. Bedding, bugs and teats-Evaluating environmental risks of intramammary infection. Pages 85-93 in Proc. Ann. Meeting Natl. Mastitis Council. NMC, St. Petersburg, FL.

Ruegg, P. L., and J. C. F. Pantoja. 2013. Understanding and using somatic cell counts to improve milk quality. Ir. J. Agric. Food Res. 52:101-117.

SAS. 2002. User's Guide. Version 9.1. SAS Institute Inc., Cary, NC.

Schepers, A. J., T. J. G. M. Lam, Y. H. Schukken, J. B. M. Wilmink, and W. J. A. Hanekamp. 1997. Estimation of variance components for somatic cell counts to determine thresholds for uninfected quarters. J. Dairy Sci. 80:1833-1840.

Schreiner, D. A., and P. L. Ruegg. 2003. Relationship between udder and leg hygiene scores and subclinical mastitis. J. Dairy Sci. 86:3460-3465.

Schukken, Y. H., R. N. Gonzalez, G. J. Bennett, H. F. Schulte, F. L. Welcome, L. L. Tikofsky, L. Coffin, C. G. Santisteban, R. N. Zadoks, and M. J. Zurakowski. 2007. Quality Milk Production Services: 60 years of milk quality improvement in New York State. Pages 159-172 in NMC Ann. Mtg. Proc., San Antonio, TX. Natl. Mastitis Council, Verona WI.

Schukken, Y. H., R. N. Gonzalez, L. L. Tikofsky, H. F. Schulte, C. G. Santisteban, F. L. Welcome, G. J. Bennett, M. J. Zurakowski, and R. N. Zadoks. 2009. CNS mastitis: Nothing to worry about? Vet. Microbiol. 134:9-14.

Schukken, Y. H., D. J. Wilson, F. Welcome, L. Garrison-Tikofsky, and R. N. Gonzalez. 2003. Monitoring udder health and milk quality using somatic cell counts. Vet. Res. 34:579-596.

Shook, G. E. 1993. Genetic improvement of mastitis through selection on somatic cell count. Pages 563-581 in Update on Bovine Mastitis. Vet. Clin. North Am. Food Anim. Pract. Vol. 9. K. L. Anderson, ed. W. B. Saunders Co., Philadelphia, PA.

Steeneveld, W., H. Hogeveen, H. W. Barkema, J. van den Broek, and R. B. M. Huirne. 2008. The influence of cow factors on the incidence of clinical mastitis in dairy cows. J. Dairy Sci. 91:1391-1402. https://doi.org/10.3168/jds.2007-0705

Wilson, D. J., R. N. Gonzalez, and H. H. Das. 1997. Bovine mastitis pathogens in New York and Pennsylvania: Prevalence and effects on somatic cell count and milk production. J. Dairy Sci. $80: 2592-2598$

Wilson, D. J., Y. T. Grohn, G. J. Bennett, R. N. Gonzalez, Y. H. Schukken, and J. Spatz. 2007. Comparison of J5 vaccinates and controls for incidence, etiologic agent, clinical severity, and survival in the herd following naturally occurring cases of clinical mastitis. J. Dairy Sci. 90:4282-4288. https://doi.org/10.3168/jds .2007-0160. 